\title{
Multi-segment foot motion during single limb toe raises in healthy individuals
}

\author{
Kirsten Tulchin ${ }^{1,2^{*}}$, Wilshaw R Stevens $\mathrm{Jr}^{1}$, Kunal Singhal ${ }^{2}$, Young-Hoo Kwon ${ }^{2}$ \\ From 3rd Congress of the International Foot and Ankle Biomechanics Community \\ Sydney, Australia. 11-13 April 2012
}

\begin{abstract}
Background
The standing toe raise, or heel rise, requires ankle plantarflexor strength, and is often used to assess foot and ankle muscle function. There is limited research on the mechanics within the foot during this task. Houck et al., [1] found that hindfoot eversion/inversion was significantly different than controls during a bilateral toe raise task in patients with posterior tibialis tendon dysfunction. They concluded, however, that most differences in foot kinematics in this patient population occurred as an offset rather than a change in pattern of motion. However the kinematic patterns of motion during a unilateral toe raise task remain unknown. The purpose of this study was to describe the multi-segment foot kinematics during a single legged toe raise in adults without a history of foot disease.
\end{abstract}

\section{Materials and methods}

Eighteen adults (12 males/ 6 females) with a mean age of $27.5 \pm 5.8$ yrs (range: 20.0-37.4) were instructed to perform 20 unilateral single limb toe raises, while maintaining a straight knee. Subjects were required to balance during the task on their own. The full body Plug-in-Gait model (VICON, Centennial, CO, USA) was used to assess lower extremity kinematics/kinetics, and the TSRHC kinematic multi-segment foot model [2] was applied bilaterally. Custom-written MATLAB code was used to automate the identification of each toe raise based on the position, velocity and acceleration of the heel marker on the stance limb. A single side was chosen from each subject, with a minimum of 15 completed toe raises selected for analysis for each individual. Maximal vertical excursion of the heel was determined by

\footnotetext{
* Correspondence: Kirsten.Tulchin@tsrh.org

'Movement Science Laboratory, Texas Scottish Rite Hospital for Children, Dallas, Texas, 75219, USA

Full list of author information is available at the end of the article
}

the displacement of the posterior calcaneus marker and was normalized relative to foot length (heel marker to metatarsal heads during the static trial.) Descriptive statistics were derived for hindfoot motion and forefoot motion (triplanar) and normalized heel excursion.

\section{Results}

Normalized heel excursion was found to be correlated to sagittal plane hindfoot and forefoot range of motion $\left(r^{2}=0.59\right.$ and $r^{2}=0.49$, respectively $)$ and peak ankle power generation $\left(\mathrm{r}^{2}=0.63\right)$. There were strong correlations in the timing of peak heel excursion and the occurrence of peak hindfoot plantarflexion $\left(\mathrm{r}^{2}=0.89\right)$, peak forefoot plantarflexion $\left(\mathrm{r}^{2}=0.63\right)$ and peak ankle power generation $\left(\mathrm{r}^{2}=0.59\right)$.

There was slight hindfoot varus and forefoot eversion noted during the heel rise, however the pattern of motion in the coronal plane was not consistent across subjects or trials. Those that exhibited a hindfoot varus pattern (VAR group) had slightly higher coronal hindfoot range of motion than those that $\operatorname{did}$ not $\left(8.6^{\circ} \mathrm{vs}\right.$. $\left.5.1^{\circ}, \mathrm{p}<0.001\right)$ while those that did not have a varus pattern (NON-Var group) exhibited more hindfoot internal rotation $\left(16.6^{\circ}\right.$ vs. $\left.8.6^{\circ}, \mathrm{p}<0.001\right)$. Most differences between groups occurred at the hindfoot, with minimal differences at the forefoot. There was no significant difference in normalized heel excursion between the two groups $(\mathrm{p}=0.241)$. Despite instructions to keep the knee straight, mean knee flexion was approximately $13.4 \pm$ $5.5^{\circ}$ across all subjects, with a total range of motion of slightly over $7^{\circ}$.

\section{Conclusions}

Kinematic patterns of motion within the foot during a single limb toe raises were variable among healthy young adults. Most significant differences across patterns occurred within the hindfoot, with minimal changes 
noted at the forefoot, which suggests that proximal motion at other joints plays a crucial role in multisegment foot kinematics. Specifically, the effect of the control and location of the center of mass relative to the foot warrants further investigation.

\section{Author details}

${ }^{1}$ Movement Science Laboratory, Texas Scottish Rite Hospital for Children, Dallas, Texas, 75219, USA. ²Department of Kinesiology, Texas Woman's

University, Denton, Texas, 76207, USA.

Published: 10 April 2012

\section{References}

1. Houck J, Neville C, Tome J, Flemister A: Foot kinematics during a bilateral heel rise test in participants with stage II posterior tibialis tendon dysfunction. J Orthop Sports Phys Ther 2009, 39:593-603.

2. Tulchin $K$, Orendurff $M$, Adolfsen $S$, Karol $L$ : Effect of walking speed on multi-segment foot kinematics in adults". J Appl Biomech 2009, 25:377-386.

doi:10.1186/1757-1146-5-S1-P29

Cite this article as: Tulchin et al: Multi-segment foot motion during single limb toe raises in healthy individuals. Journal of Foot and Ankle Research 2012 5(Suppl 1):P29.

Submit your next manuscript to BioMed Central and take full advantage of:

- Convenient online submission

- Thorough peer review

- No space constraints or color figure charges

- Immediate publication on acceptance

- Inclusion in PubMed, CAS, Scopus and Google Scholar

- Research which is freely available for redistribution

Submit your manuscript at www.biomedcentral.com/submit
C Biomed Central 